\title{
SOME COMPANION INEQUALITIES TO JENSEN'S INEQUALITY
}

\author{
M. Matić AND J. PeČARIĆ
}

Abstract. We prove a pair of general companion inequalities to Jensen's inequality in its discrete and integral form. Slater's inequality as well as the generalization of the counterpart to Jensen's inequality along with some further results are deduced from these general inequalities.

Mathematics subject classification (1991): 26D15, 26A51, 26 B25.

Key words and phrases: Convex functions, inequalities, Jensen's inequality.

\section{REFERENCES}

[1] S. S. DRAGOMIR AND C. J. GoH, A counterpart of Jensen's discrete inequality for differentiable convex mappings and applications in information theory, Math. Comput. Modelling 24 (2) (1996), 1-11.

[2] D. S. MitrinoviĆ, J. E. PeČARIĆ AND A. M. FinK, Classical and new inequalities in analysis, Kluwer Academ. Publ., 1993.

[3] J. E. PEČARIĆ, A multidimensional generalization of Slater's inequality, J. Approx. Theory 44 (3) (1985), 292-294.

[4] J. E. PEČARIĆ AND D. ANDRICA, Abstract Jessen's inequality for convex functions and applications, Mathematica (Cluj) 29 (52) (1987), 61-65.

[5] A. W. Roberts and D. E. VArberg, Convex Functions, Academic Press, New York-London, 1972.

[6] W. Rudin, Real and complex analysis, McGraw-Hill, London, 1970.

[7] M. L. SLATER, A companion inequality to Jensen's inequality, J. Approx. Theory 32 (1981), 160-166. 